\title{
Standounkt
}

\section{Wer soll die Energiewende im Wohngebäudebereich bezahlen?}

\author{
Der verantwortliche Umgang mit begrenzten Ressourcen und \\ die Vorsorge zu einer intakten Umwelt für künftige Generatio- \\ nen bilden eine wesentliche Klammer der klimapolitischen \\ Diskussion im Deutschen Mieterbund. Daneben existiert ein \\ sehr konkretes Eigeninteresse am Thema, das durch die \\ Energiepreisentwicklung der Vergangenheit gespeist wird. \\ Von Lukas Siebenkotten
}

$I_{\mathrm{w}}^{\mathrm{n}}$ keinem anderen Bereich sind die Wohnkosten so nachhaltig angestiegen wie für Heizung, Strom und warmes Wasser. Die energiepolitische Wende, zu der eine deutliche Steigerung der Energieeffizienz gehört, ist auch notwendig, um den Anteil der Wohnkosten beherrschen zu können, der an die unweigerlich steigenden Energiekosten gekoppelt ist.

Der Deutsche Mieterbund hat keinen Zweifel daran gelassen, dass er Vorschläge mitträgt, die neben Staat und Eigentümern die belastbaren Mieter an den Kosten der Klimainvestitionen beteiligt. Man darf die Armen nicht als soziale Schutzwälle für Klientelpolitik missbrauchen, aber man muss ihnen ernsthaft helfen, wenn man die belastbaren Bürger an der Vorwärtsfinanzierung des Klimaschutzes beteiligen will. Dabei ist es im Ergebnis egal, ob die Energiekosten aufgrund einer stärkeren Besteuerung des Ressourcenverbrauchs ansteigen, aufgrund der Umlagekosten einer flächenhaften energetischen Modernisierung oder aufgrund von Energiemarktentwicklungen. Die Folgen sind von den einkommensschwächsten Mietern immer am schwersten zu verkraften. Was können wir im Rahmen der staatlichen Förderung tun, um soziale Verträglichkeit und ökologische Notwendigkeit zusammenzuführen?

\section{Warmmietenneutrale Modernisierung}

Die staatliche Förderung energetischer Sanierung müsste sich in erster Linie an den erzielten Energieeinspareffekten und nicht an den Investitionskosten ausrichten. Wäre dieses Ziel die konsequente Leitlinie von Förderung, wäre es schon bei heutigen Preisen und mit dem vorhandenen Mietrecht möglich, die modernisierungsbedingten Mieterhöhungen in ein ausgewogenes Verhältnis zu den eingesparten Heizkosten zu bringen. Dass eine solche Ausrichtung der Förderpolitik möglich ist, belegen zahlreiche Beispiele. Die gängige Modernisierungspraxis sieht allerdings leider anders aus. Man muss an dieser Stelle daran erinnern, dass die eigentliche Zukunftsbaustelle der ökologischen Modernisierung nicht der Neubau ist, sondern der vorhandene Wohnungsbestand.

Vor allem brauchen wir Grenzwerte und Standards. Nur auf Freiwilligkeit zu setzen, wäre angesichts des Zeitdrucks, unter dem der Klimaschutz steht, grob fahrlässig. Ob diese Grenzwerte über Landesklimaschutzgesetze oder über eine veränderte Energieeinsparverordnung, die auch im Wohnungsbestand greift, verankert werden sollten, muss hier nicht vertieft werden. Neben die Festlegung von Grenzwerten müssen verlässliche und langfristige staatliche Rahmenbedingungen, insbesondere Fördermittel, treten.

Der Gesetzentwurf der Bundesregierung zur steuerlichen Förderung energetischer Investitionen, der über eine jährliche Abschreibung von zehn Prozent die Investitionskosten über zehn Jahre verteilt, ist vor allem aufgrund der befürchteten Steuerausfälle - Schätzung von 900
Millionen für die Länder - im Bundesrat abgelehnt worden und beim Vermittlungsausschuss gelandet. Weil die Wahrnehmung dieser Sonderabschreibungsmöglichkeit als Alternative zur Inanspruchnahme der Förderung der Kreditanstalt für Wiederaufbau gedacht ist, hat der Deutsche Mieterbund gesagt: Wir sind dafür, wenn die ersparte Steuer als Fördertatbestand in Form einer Pauschale (der steuerpraktisch einzigen Möglichkeit) von den umlagefähigen Kosten der Modernisierung abgezogen werden muss. Denn nur dann würde die Steuerabschreibung auch die mit elf Prozent überwälzbaren Modernisierungskosten vermindern und damit nicht nur dem Investor, sondern auch dem Mieter nutzen.

\section{Ohne Ordnungspolitik geht es nicht}

Viele Diskussionen über angemessene sowie klima- und mieterverträgliche Förderung müssten wir gar nicht führen, wenn dafür gesorgt wäre, dass es für einkommensschwächere Mieter eine soziale Abfederung gibt. Deshalb brauchen wir flankierende Maßnahmen für die Mieter in den unteren Einkommensgruppen. Der Deutsche Mieterbund hat dazu unter anderem die Einführung eines sogenannten „Klimawohngelds“ vorgeschlagen, also einer zusätzlichen Kategorie im Wohngeld, die es berücksichtigt, wenn aufgrund einer energetischen Sanierung die Miete höher ist als ohne dieselbe.

Wenn die soziale Dimension der Kosten des Klimaschutzes im Wohngebäudesektor beachtet wird und fachkundige unabhängige Beratung mit einer ausschließlich am Grad der erzielten Steigerung der Energieeffizienz orientierten Förderung einhergeht, ist Wohnen in Deutschland in Zukunft auch im Zeichen der Energiewende bezahlbar.

I AUTOR + KONTAKT

Lukas Siebenkotten ist Direktor des Deutschen Mieterbunds e. V. (DMB).

Deutscher Mieterbund e.V., Littenstraße 10 10179 Berlin. Tel.: +49 30 22323-0 E-Mail: info@mieterbund.de 


\section{Lizenzhinweis}

Die Beiträge in ÖkologischesWirtschaften werden unter der Creative-Commons-Lizenz "CC 4.0 Attribution Non-Commercial No Derivatives" veröffentlicht. Im Rahmen dieser Lizenz muss der Autor/Urheber stets genannt werden, das Werk darf nicht bearbeitet, abgewandelt oder in anderer Weise verändert und außerdem nicht kommerziell genutzt werden. Die digitale Version des Artikels bleibt für zwei Jahre Abonnent/innen vorbehalten und ist danach im Open Access verfügbar. 